\title{
Photochemical Inactivation Analysis of Temporal Dynamics of Postsynaptic Native AMPA Receptors in Hippocampal Slices
}

\author{
Haruyuki Kamiya \\ Department of Neurobiology, Hokkaido University School of Medicine, Sapporo 060-8638, Japan
}

Postsynaptic expression of AMPA-type glutamate receptors (AMPAR) is more mobile than previously thought. Much evidence suggests that AMPAR are delivered from intracellular reserved pools to postsynaptic sites in a constitutive, as well as activity-dependent manner by exocytosis, lateral diffusion, or diffusional trapping. These notions were supported by optical monitoring of AMPAR subunits labeled with macromolecular tags such as GFP or Immunobeads, although it remains uncertain whether the mode and rate of synaptic delivery are similar to native "unlabeled" receptors. To reveal the real-time dynamics of native AMPAR in situ, photochemical inactivation of surface receptors using 6-azido-7-nitro-1,4-dihydroquinoxaline-2,3-dione (ANQX), a photoreactive AMPAR blocker, was adopted for acute hippocampal slices of mice. Because of the irreversible block due to cross-link formation between ANQX and surface AMPAR, recovery of EPSPs after photoinactivation reflects the time course of synaptic delivery of intracellular AMPAR. Brief UV illumination with fast application of ANQX resulted in persistent suppression of EPSPs for a prolonged period of up to $3 \mathrm{~h}$, suggesting minimal synaptic delivery of AMPAR by exocytosis in the resting condition. Kinetic analysis of EPSP recovery clarified that the supply of postsynaptic AMPAR from the intracellular pool is dominated in the initial, but not in the later, phase of long-term potentiation (LTP). These results suggest that constitutive synaptic delivery is minimal in the resting condition at intact hippocampal synapses in a time scale of hours, while postsynaptic AMPAR are replaced with those in intracellular pools almost exclusively in an activity-dependent manner, typically shortly after LTP induction.

\section{Introduction}

Excitatory synaptic transmission in the mammalian CNS is mostly mediated by AMPA-type glutamate receptors (AMPAR), and the number and precise localization of postsynaptic AMPAR are a critical determinant of the efficacy of transmission. Postsynaptic expression of AMPAR is highly mobile (Borgdorff and Choquet, 2002; Kennedy and Ehlers, 2011), and AMPAR traffic supports enhanced transmission during long-term potentiation (LTP) in the hippocampus, a leading candidate cellular process underlying memory (Malinow and Malenka, 2002; Bredt and Nicoll, 2003). Synaptic AMPAR have been shown to be delivered to the postsynaptic site by exocytosis from intracellular pools (Nishimune et al., 1998; Shi et al., 1999; Hayashi et al., 2000; Kennedy at al., 2010), by lateral diffusion from extrasynaptic sites (Makino and Malinow, 2009; Opazo and Choquet, 2011), or by diffusional trapping to postsynaptic slots (Ehlers et al., 2007; Opazo et al., 2010). Mobility of AMPAR is regulated by direct, as well as indirect, interactions with scaffold proteins (Ehrlich and Malinow, 2004; Tomita et al., 2004), and their trafficking is reg-

Received Feb. 15, 2012; revised March 19, 2012; accepted March 25, 2012.

Author contributions: H.K. designed research; H.K. performed research; H.K. analyzed data; H.K. wrote the paper.

This work was supported by Grant-in-Aid for Scientific Research (21300146) from the Japan Society for the Promotion of Science.

Correspondence should be addressed to Dr. Haruyuki Kamiya, Department of Neurobiology, Hokkaido University

School of Medicine, Sapporo 060-8638, Japan. E-mail: kamiya@med.hokudai.ac.jp.

DOI:10.1523/JNEUROSCI.0720-12.2012

Copyright $\odot 2012$ the authors $\quad 0270-6474 / 12 / 326517-08 \$ 15.00 / 0$ ulated in both a constitutive and activity-dependent manner (Shi et al., 2001). These notions were mainly supported by fluorescence imaging of AMPAR subunits labeled with macromolecular tags such as GFP (Shi et al., 1999) or other fluorescent proteins (Makino and Malinow, 2009; Kennedy et al., 2010) in cultured slices. Optical tracking of immunobeads (Borgdorff and Choquet, 2002) or quantum dots (Ehlers et al., 2007) labeled with specific antibodies against AMPAR subunits were also used in cultured hippocampal neurons, although it remains uncertain whether the mode and rate of synaptic delivery of native AMPAR are similar to exogenously transfected or macromolecular tagged ones. A promising alternative approach to reveal the real-time dynamics of native AMPAR in situ is photoinactivation by 6-azido-7nitro-1,4-dihydroquinoxaline-2,3-dione (ANQX) (Chambers et al., 2004), a photoreactive irreversible antagonist which has been used in cultured hippocampal neurons (Adesnik et al., 2005). Due to crosslink formation with ligand binding sites of AMPAR (Cruz et al., 2008), ANQX irreversibly binds and blocks AMPAR-mediated responses after UV illumination. Because of the irreversible nature of the reaction, recovery of EPSPs after photoinactivation is expected to reflect synaptic delivery of AMPAR from intracellular pools, and therefore this approach permits kinetic analysis of surface delivery of AMPAR. Although a previous study failed at successful photoinactivation in acute hippocampal slices (Adesnik et al., 2005) in which LTP was induced readily and reproducibly, the authors predicted that fast perfusion of ANQX may enable efficient photoinactivation of AMPAR even in acute slice preparations. 
In this study, experimental conditions for efficient photoinactivation of AMPAR with ANQX in acute slice preparation were explored. It has been shown that local fast application of ANQX with brief UV illumination was sufficient for photoinactivation of synaptic AMPAR in hippocampal slices. Since long-term recording up to several hours is feasible in acute slices, an attempt was made to reveal the time course of synaptic delivery of native AMPAR at intact synapses during baseline transmission and induction and maintenance of LTP to clarify the temporal dynamics of constitutive, as well as activity-dependent, AMPAR trafficking in situ.

\section{Materials and Methods}

Animals and slice preparations. C57BL/6 J mice of either sex were used in the present study, and were treated according to the guidelines for the care and use of laboratory animals of Hokkaido University. Transverse hippocampal slices $400 \mu \mathrm{m}$ thick were prepared from 14- to 21-d-old mice as described previously (Kamiya et al., 2002; Shimizu et al., 2008). Animals were anesthetized with ether and the brain was dissected out in an ice-cold sucrose solution containing the following (in mM): $40 \mathrm{NaCl}$, $25 \mathrm{NaHCO}_{3}, 10$ glucose, 150 sucrose, $4 \mathrm{KCl}, 1.25 \mathrm{NaH}_{2} \mathrm{PO}_{4}, 0.5 \mathrm{CaCl}_{2}$, and $7 \mathrm{MgCl}_{2}$. Transverse slices were cut using a PRO 7 microslicer (Dosaka-EM) and incubated for $\sim 1 \mathrm{~h}$ in the above solution. Then, the sucrose-containing solution was replaced with artificial CSF (ACSF) containing the following (in $\mathrm{mM}$ ): $127 \mathrm{NaCl}, 1.5 \mathrm{KCl}, 1.2 \mathrm{KH}_{2} \mathrm{PO}_{4}, 26$ $\mathrm{NaHCO}_{3}, 10$ glucose, $2.4 \mathrm{CaCl}_{2}$, and $1.3 \mathrm{MgCl}_{2}$, and the slices were kept in an interface-type chamber saturated with $95 \% \mathrm{O}_{2}$ and $5 \% \mathrm{CO}_{2}$.

Electrophysiology. Whole slices were continuously perfused at $\sim 2 \mathrm{ml} /$ min with the above ACSF. In addition, the slice surface of the recording site was locally perfused with the above solution at $\sim 0.2 \mathrm{ml} / \mathrm{min}$ through a flow pipe with a $250 \mu \mathrm{m}$ open-tip diameter connected to an electromagnetic valve system (Valve Bank; Automate Scientific) for faster exchange of solution at the recording sites. It should be noted that in these conditions, washout of ANQX was not instantaneous, but took up to several tens of minutes (see Fig. $2 B$, open circles). For experiments in CA1 synapses, stimulating and recording electrodes were placed in the stratum radiatum in the CA1 region. Electrical stimuli of $100 \mu$ s duration were given every $10 \mathrm{~s}$, except in Figure 7 experiments in which alternating stimuli were delivered through two-independent electrodes placed in the stratum radiatum of CA 1 every $20 \mathrm{~s}$ (two pathway experiment). The tip of the glass microelectrode (10 $\mu \mathrm{m}$ tip diameter) for extracellular recording was placed at a depth of $\sim 100 \mu \mathrm{m}$ from the surface of the slice to facilitate faster exchange of the solution around the recording site. In experiments on the mossy fiber-CA3 synapse in Figure 3, a modified ACSF with high divalent cations $\left(4 \mathrm{mM} \mathrm{CaCl}_{2}\right.$ and $4 \mathrm{~mm} \mathrm{MgCl}_{2}$ ) was used to prevent recruitment of polysynaptic responses. Mossy fibers were stimulated at the granule cell layer of the dentate gyrus, and the evoked field EPSPs were recorded in the stratum lucidum of the CA3 region. DCG-IV was applied at the end of experiments to confirm that mossy fibers were selectively stimulated (Kamiya et al., 1996). All recordings were made at room temperature $\left(24-26^{\circ} \mathrm{C}\right)$. Field EPSPs were acquired and analyzed with pClamp 10 software (Molecular Devices). Data are expressed as the mean \pm SEM. Statistical analysis was performed using unpaired $t$ test unless otherwise stated, and $p<0.05$ was accepted for statistical significance.

Photochemical inactivation of AMPAR. ANQX, a photoreactive derivative of the AMPAR blocker DNQX, was custom synthesized according to the procedures described by Chambers et al. (2004) and purchased from Wako Pure Chemicals. Stock solution of ANQX was prepared by dissolving in dimethyl sulfoxide at $100 \mathrm{~mm}$, and diluted to the final concentration of $100 \mu \mathrm{M}$ with ACSF for each experiment. For photoinactivation of native AMPAR in situ, $100 \mu \mathrm{M}$ ANQX dissolved in ACSF was locally applied through the above flow pipe for $1 \mathrm{~min}$ and left for $2 \mathrm{~min}$ to reach maximal suppression of EPSPs (see also Fig. $1 D$ ), assuring that ANQX reached the synaptic site sufficiently. Then, UV light (330-385 $\mathrm{nm}$ bandpass filtered mercury lamp source) was illuminated for $5 \mathrm{~s}$ through a $40 \times$ objective (NA 0.80 ) equipped with an upright microscope (BX 50WI, Olympus) (Adesnik et al., 2005). In preliminary experiments, this illumination condition without ANQX application did not affect
EPSPs significantly, therefore possible phototoxic damage due to UV illumination on the molecular machinery for synaptic transmission was excluded. To measure time-course of recovery, single exponential fits were calculated for data in a $60 \mathrm{~min}$ period after photoinactivation. It should be mentioned that the initial 2 min was excluded from analysis, since EPSPs were decreasing initially in some experiments possibly due to relatively slow perfusion in acute slice preparations. ANQX is known to change to highly reactive nitrene upon UV illumination (Cruz et al., 2008). If ANQX does not form a cross-link with AMPAR, it converts to FQX, a reversible AMPAR blocker with weaker affinity $\left(K_{\mathrm{d}}=7.6 \mu \mathrm{M}\right)$ than ANQX $\left(K_{\mathrm{d}}=1.0 \mu \mathrm{M}\right)$. To examine the effect of photoproduct FQX, ANQX solution was UV irradiated for a prolonged period of up to several tens of seconds in advance, and then applied with the same protocol as ANQX (Fig. $2 B$, open triangles).

\section{Results}

\section{Photoinactivation of native AMPAR in acute hippocampal slices}

First, optimal conditions for fast application and fast removal of ANQX were explored in acute hippocampal slices. A previous study suggested that cross-link formation between photolyzed ANQX and surface AMPAR requires fast perfusion of an ANQXcontaining solution (Adesnik et al., 2005). Therefore, the surfaces of the recording sites were locally perfused at $\sim 0.2 \mathrm{ml} / \mathrm{min}$ using a flow pipe with a wide open-tip diameter $(250 \mu \mathrm{m})$, and the position of the tip was carefully adjusted under a microscope to maximize perfusion of the recording sites. As predicted, extensive local perfusion of the recording sites with ANQX in combination with brief UV illumination (Fig. 1A) resulted in persistent suppression of EPSPs (Fig. $1 B, C)$. Even under these conditions, complete exchange of solution at the synaptic sites seemed to be delayed for a couple of minutes, probably because of a diffusion barrier due to the complex microenvironment of intact synapses and surrounding glia in slice preparations. One minute application of $100 \mu \mathrm{M}$ ANQX was followed by a 2 min equilibrium period to reach maximal suppression of EPSPs, and then UV illumination for $5 \mathrm{~s}$ was applied (Fig. 1D). It should be noted that EPSPs were decreased during ANQX application and quickly and markedly increased upon UV illumination (Fig. 1C), as explained by the decrease in the apparent affinity of photolyzed ANQX to AMPAR (Chambers et al., 2004; Adesnik et al., 2005). This clearly demonstrated that ANQX was photolyzed efficiently at synaptic sites in acute slice preparations. After an initial small recovery for $\sim 10-20 \mathrm{~min}$, EPSPs did not change during a prolonged observation period up to $3 \mathrm{~h}(57 \pm 4 \%$ of control at $180 \mathrm{~min}$ after UV illumination, $n=13$; Fig. $1 C$ ). Persistent suppression of EPSPs after photoinactivation suggests that constitutive AMPAR delivery from the intracellular pool is minimal at native synapses in acute slices. The initial small recovery may reflect washout of unphotolyzed ANQX and side product FQX, both of which are reversible blockers of AMPAR. FQX is formed by intramolecular reactions if ANQX fails to form a cross-link with AMPAR upon UV illumination (Cruz et al., 2008). Initial recovery was fitted with single exponential function and the time constant was $14.5 \pm 2.8 \mathrm{~min}(n=13)$. Almost no effect on presynaptic fiber volley potentials and compound action potentials of axons, which suggested minimal phototoxic damage on excitability of axons, were observed under these conditions (Fig. $1 B$, asterisks). Successful photoinactivation of ANQX and cross-link formation with postsynaptic AMPAR were also supported by the findings below. First, suppression of EPSPs readily accumulated upon repeated photoinactivation of four times at $15 \mathrm{~min}$ intervals $(41 \pm$ $3 \%$ of control at $60 \mathrm{~min}$ after the fourth photoinactivation, $n=8$; Fig. $1 E$ ) as expected from the irreversible block due to cross-link formation between photolyzed ANQX and AMPAR (Adesnik et al., 2005). Furthermore, application of ANQX without UV illumination 
A

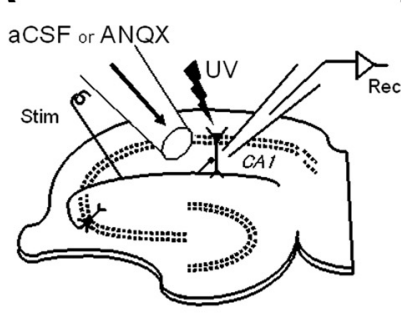

B control

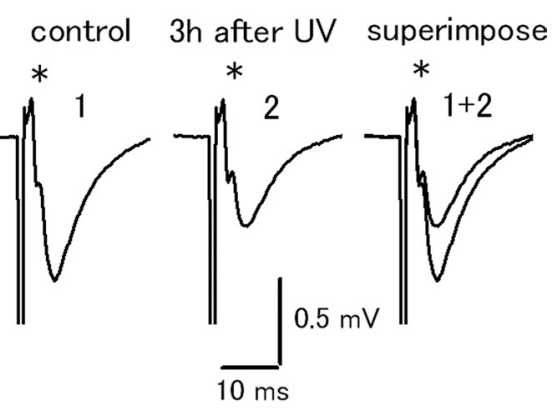

C
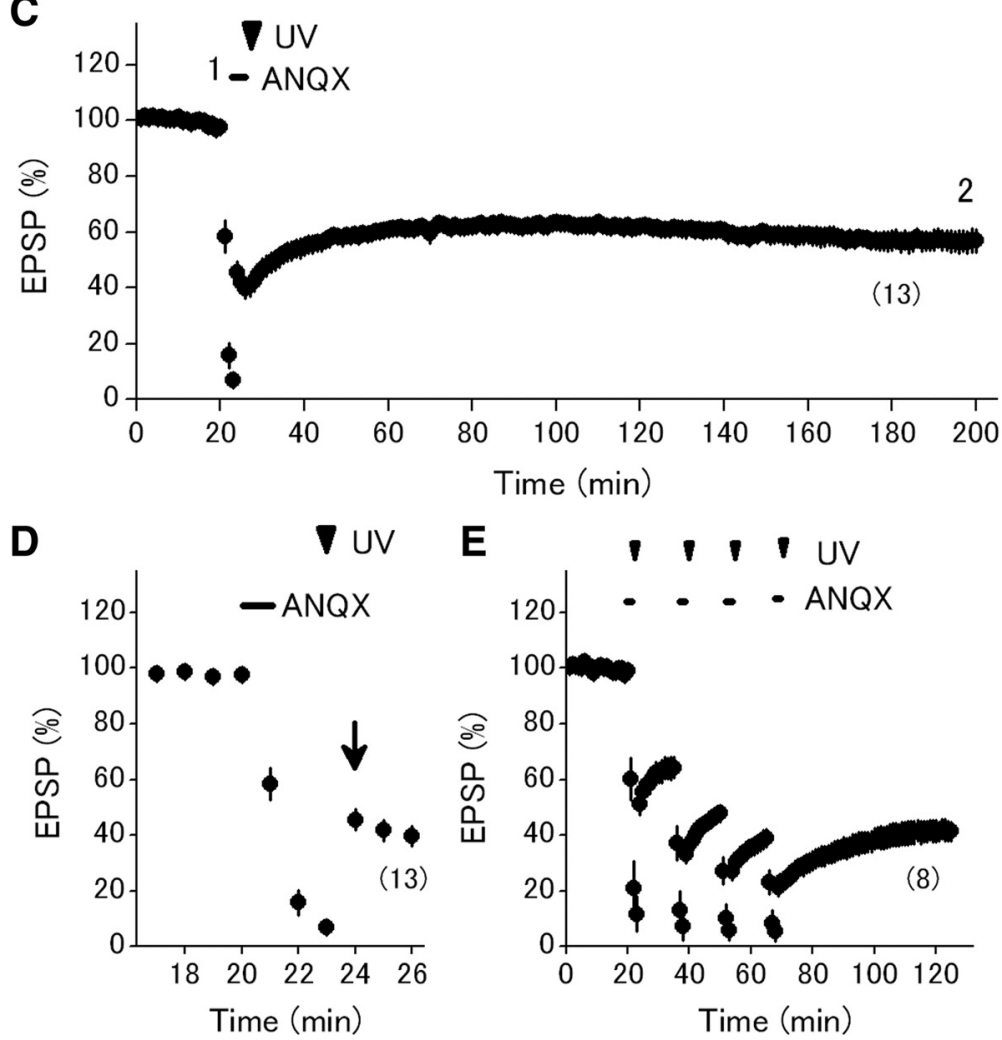

2

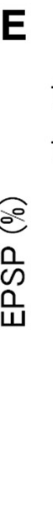

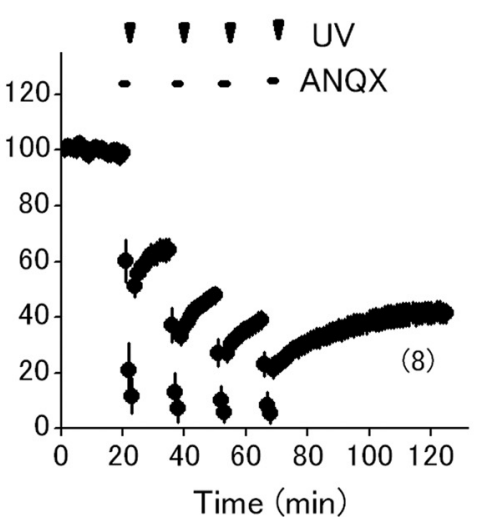

Figure 1. Photoinactivation of native AMPA receptors by photoreactive antagonist ANQX in hippocampal CA1 synapses. $\boldsymbol{A}$, Schematic drawing of the experimental arrangement. Slice surface of the recording site is extensively perfused (at $\sim 0.2 \mathrm{ml} / \mathrm{min}$ ) through a flow pipe with a wide open-tip diameter $(250 \mu \mathrm{m})$. $\boldsymbol{B}$, Effect of ANQX application with UV illumination. Specimen records show persistent suppression of EPSPs for $3 \mathrm{~h}$ with a minimal effect on presynaptic fiber volleys (asterisks). $C$, Time course of EPSPs in the above experiment. Representative traces in $\boldsymbol{B}$ are sampled at time points labeled by the numbers. $\boldsymbol{D}$, Expanded time course around photoinactivation. EPSPS quickly increased following UV illumination (arrow), confirming that ANQX was photolyzed efficiently under these conditions. $\boldsymbol{E}$, Effect of repeated photoinactivation 4 times at 15 min intervals. Data shown are mean \pm SEM. Numbers of experiments are indicated in parentheses.

suppressed EPSPs in an almost reversible manner ( $96 \pm 2 \%$ of control at $60 \mathrm{~min}$ after ANQX application, $n=13$ ) (Fig. $2 A, B$, open circles), since ANQX itself is a reversible blocker of AMPAR (Cruz et al., 2008). Time constant of recovery, as calculated with single exponential fit, was $17.9 \pm 2.1 \mathrm{~min}(n=13)$. UV illumination itself showed a minimal effect on EPSPs, excluding the possible contribution of phototoxic damage to synaptic transmission ( $99 \pm 2 \%$ of control at $60 \mathrm{~min}$ after UV illumination, $n=10$ ) (Fig. $2 \mathrm{~B}$, open diamonds). The almost reversible effect of ANQX in our experimental conditions strongly supports irreversible cross-link formation between ANQX and synaptic AMPAR upon UV illumination. In another set of experiments, an ANQX solution, which was already illuminated with UV, was applied over the same time course. The UV illuminated ANQX solution, which is thought to be mainly composed of photoproduct FQX (Cruz et al., 2008), reversibly sup- pressed to a small degree ( $28 \pm 4 \%$ of control at $60 \mathrm{~min}$ after application, $n=8$ ) (Fig. $2 B$, open triangles), as predicted from weaker affinity of FQX $\left(K_{\mathrm{d}}=7.6 \mu \mathrm{M}\right)$ for AMPAR than ANQX $\left(K_{\mathrm{d}}=1.0 \mu \mathrm{M}\right)$. It should also be noted that the recovery time course is faster than ANQX alone. Time constant of recovery in UV illuminated ANQX solution group (12.0 $\pm 0.5 \mathrm{~min}, n=$ 8) was statistically different from that in ANQX without UV illumination group $(17.9 \pm 2.1 \mathrm{~min}, n=13 ; p=0.043$, $t$ test; Fig. $2 B$ ). Reversible suppression by ANQX itself or UV-illuminated photoproduct FQX strongly suggested that ANQX or FQX acts exclusively on cell surface receptors, and hardly penetrates the cell membrane to affect intracellular receptors. This is also consistent with a study using $\mathrm{x}$-ray crystallography demonstrating selective binding of ANQX to the extracellular ligand binding core of AMPA receptors (Cruz et al., 2008).

These results suggest that postsynaptic expression of AMPAR is quite stable for prolonged periods up to $3 \mathrm{~h}$. Minimal constitutive surface delivery of native AMPAR in slice preparations was rather unexpected, so similar experiments were repeated for mossy fiber-CA3 synapses, another typical glutamatergic synapse in the hippocampus (Kakegawa et al., 2004), to test if this conclusion was also applicable to other excitatory synapses. ANQX was applied to slice surfaces of the recording sites in the stratum lucidum of the CA3 region (Fig. 3A). Again, after an initial small recovery, EPSPs did not change during a prolonged observation period up to $3 \mathrm{~h}(68 \pm 5 \%$ of control at $180 \mathrm{~min}$ after UV illumination, $n=6$ ) (Fig. $3 B, C$, closed circles). Application of ANQX alone suppressed EPSPs in an almost reversible manner $(100 \pm 4 \%$ of control at $180 \mathrm{~min}$ after ANQX application, $n=7$ ) (Fig. $3 B$, open circles). UV illumination alone showed a minimal effect on EPSPs $(104 \pm 6 \%$ of control at $180 \mathrm{~min}$ after UV illumination, $n=5$ ) (Fig. $3 B$, open diamonds). Almost the same results in two representative synapses, namely CA1 synapses and mossy fiber-CA3 synapses, strongly suggest that photoinactivation of postsynaptic AMPAR by ANQX is generally applicable to glutamatergic synapses in brain slice preparations. More importantly, constitutive surface delivery of native AMPAR may be quite slow, if any, in a time scale of hours.

\section{Photoinactivation analysis of LTP}

This approach was used to analyze the expression mechanism of LTP, an activity-dependent form of plasticity. Theta-burst stimulation (TBS) (Larson et al., 1986; Nguyen and Kandel, 1997), which consists of 10 bursts of four pulses at $100 \mathrm{~Hz}$ with an interval of $200 \mathrm{~ms}$, induced robust LTP (145 $\pm 11 \%$ of control at 60 min after TBS, $n=9$ ) (Fig. $4 A, B$, closed circles). After stable 
potentiation was established, ANQX application with UV illumination at $60 \mathrm{~min}$ after TBS also caused persistent suppression of potentiated EPSPs. The time course of initial recovery of EPSPs after photoinactivation was almost the same as that of the unpotentiated synapses shown in Figure $1 C$, possibly reflecting the time course of washout of unphotolyzed ANQX and side product FQX. This result suggests that acceleration of synaptic delivery of AMPAR does not contribute to maintenance of LTP later than 60 min after induction. In another series of experiments, photoinactivation was applied at $5 \mathrm{~min}$ after TBS (Fig. $4 A, C$, open circles). In these experiments, initial recovery was faster than with photoinactivation applied at $60 \mathrm{~min}$ after TBS. Time constants of recovery, as calculated with a single exponential fit, were statistically different between the 5 min group $(10.2 \pm 3.4 \min , n=6)$ and $60 \mathrm{~min}$ group $(26.4 \pm 5.0 \mathrm{~min}, n=9 ; p=0.033, t$ test $)$, suggesting that surface delivery of AMPAR transiently accelerated after LTP induction and returned to basal levels by $60 \mathrm{~min}$ after TBS. It should be mentioned that potentiation was not stable, but slowly decayed for the initial one hour after TBS (Fig. 4A, closed circles). Slow decay of potentiation may overlay the time course of recovery after photoinactivation. However, the decaying potentiation may decelerate, rather than accelerate, the time course of recovery after photoinactivation; therefore, it can be concluded that surface delivery of AMPAR is accelerated shortly after LTP induction.

Acceleration in the recovery in the early period after LTP induction may be accompanied by an increase in the fraction of recovery. For quantitative comparison of fractional recovery between the $5 \mathrm{~min}$ and $60 \mathrm{~min}$ groups, EPSPs at $60 \mathrm{~min}$ after photoinactivation in the two groups was compared. Data in the 5 min group (96 \pm $8 \%$ of control, $n=6$ ) were not significantly larger than in the $60 \mathrm{~min}$ group $(82 \pm 7 \%, n=9 ; p=0.22, t$ test $)$.

Since the photoinactivation protocol used in this study requires extensive local perfusion around the recording sites and UV illumination, these manipulations may perturb cellular processes involved in LTP induction. To test this possibility, TBS was applied at $60 \mathrm{~min}$ after photoinactivation (Fig. 5A). For comparison, EPSPs were normalized to those during the 20 min before TBS (Fig. 5B), and the magnitude of potentiation at $60 \mathrm{~min}$ after TBS ( $145 \pm 5 \%, n=10)$ was almost identical to that without preceding photoinactivation (145 $\pm 11 \%, n=9$, data in Fig. $4 A$, closed circles; $p=0.95, t$ test). This result suggests that neither UV illumination nor cross-link formation with ANQX affects synaptic plasticity at CA1 synapses under these conditions. Since ANQX binds with the extracellular ligand binding core, cross-link formation may not strongly affect the cytoplasmic C-terminal domain, which is known to influence receptor trafficking (Bredt and Nicoll, 2003).

To test whether surface delivery of AMPAR is activated during LTP induced by high-frequency stimulation (HFS) (Huang and Kandel, 1994), another conditioning protocol often used for LTP in-
A
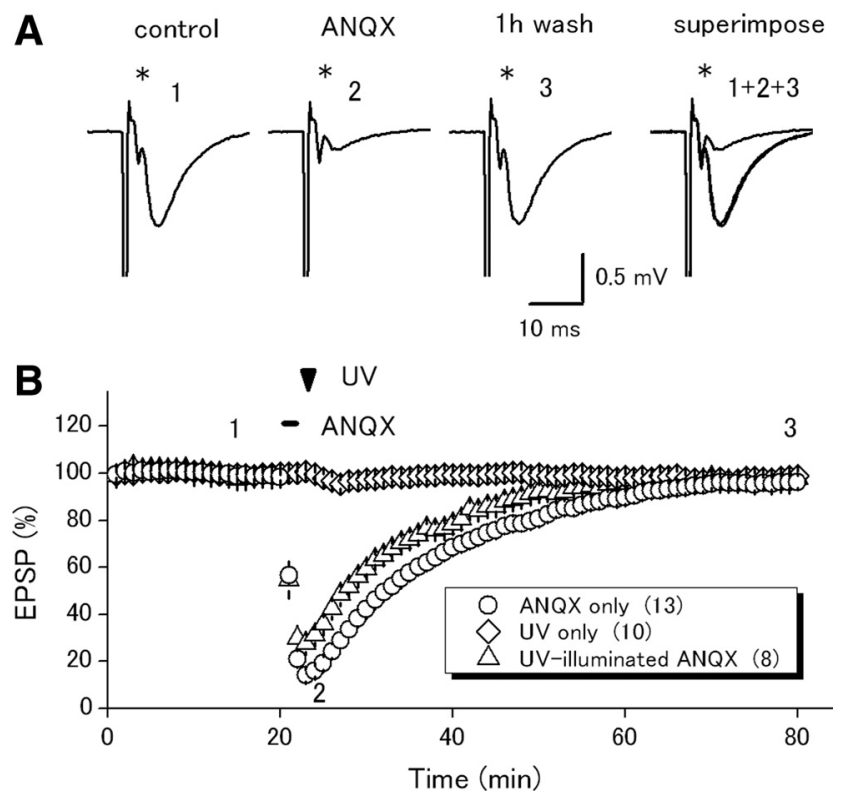

Figure 2. Reversible suppression of EPSPs by ANQX application without UV illumination. $A$ Effect of ANQX application alone on EPSPs at CA1 synapses. Asterisks show presynaptic fiber volleys. $\boldsymbol{B}$, Summary of time course of EPSPs in the above experiments (open circles). Data in similar experiments with UV illumination alone are shown in the same graph (open diamonds) for reference. In another set of experiments, already UV-illuminated ANQX was applied (open triangles) to examine the effect of photoproduct FQX. Numbers of experiments are indicated in parentheses.

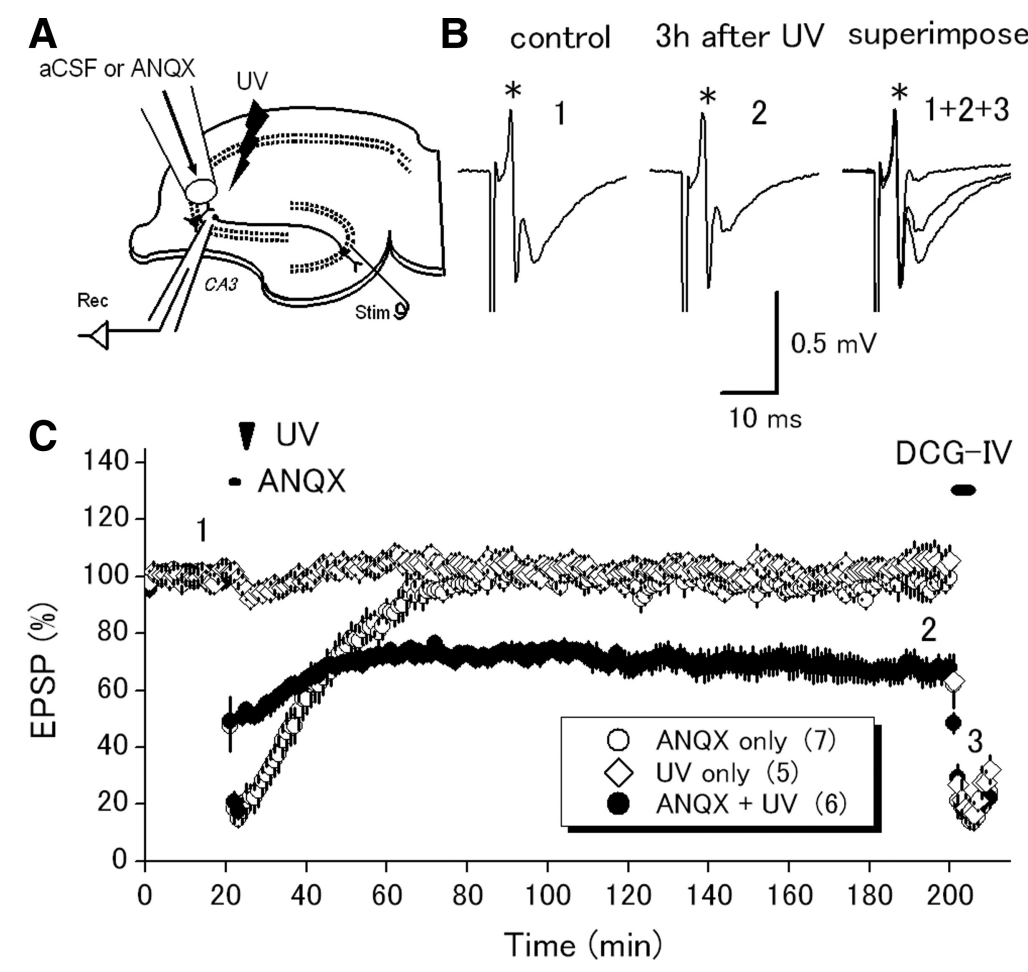

Figure 3. Photoinactivation of native AMPA receptors in mossy fiber-CA3 synapses. $A$, Schematic diagram of the experimental arrangement. Slice surface of the recording site (stratum lucidum) is locally perfused with the same flow pipe. $\boldsymbol{B}$, Effect of ANQX application with UV illumination. Specimen records show persistent suppression of EPSPs lasting for $3 \mathrm{~h}$, with a minimal effect on presynaptic fiber volleys (asterisks). C, Time course of EPSPs in the above experiment (closed circles). For comparison, data in similar experiments with ANQX application alone (open circles) or with UV illumination alone (open diamonds) are superimposed. DCG-IV $(1 \mu \mathrm{M})$ was applied at the end of experiments to confirm that the mossy fibers were selectively stimulated. Numbers of experiments are indicated in parentheses. 
A
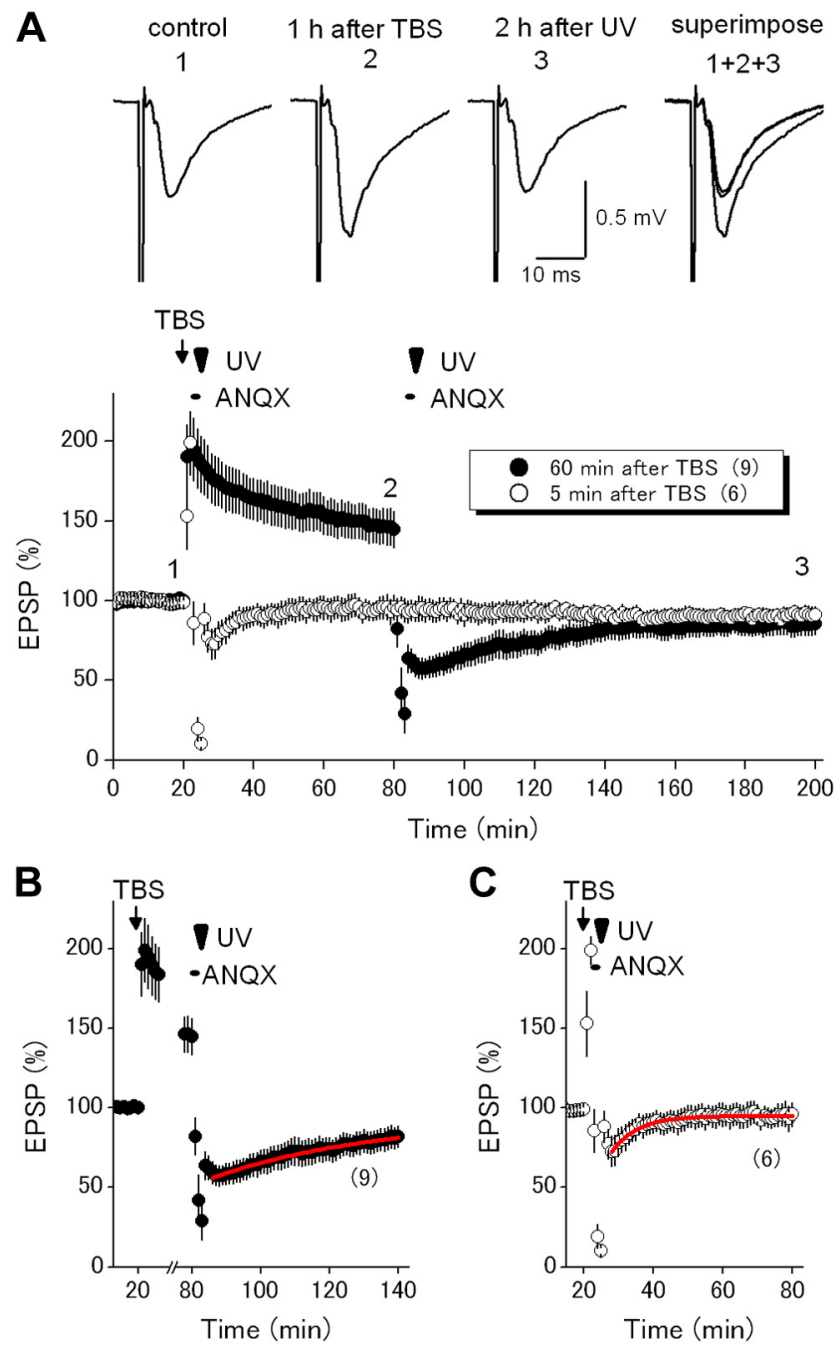

Figure 4. Accelerated synaptic delivery in the initial, but not in the later, phase of LTP induced by TBS. A, Effect of photoinactivation either $5 \mathrm{~min}$ (open circles) or $60 \mathrm{~min}$ (closed circles) after TBS (10 bursts of 4 pulses at $100 \mathrm{~Hz}$ with an interval of $200 \mathrm{~ms}$ ). Representative traces show data in the 60 min group. $\boldsymbol{B}$, Expanded time course around photoinactivation applied $60 \mathrm{~min}$ after TBS. Data points from 27 to $77 \mathrm{~min}$ are curtailed for clarity. Red line represents single-exponential fit of the time course of recovery after photoinactivation. C, Same as $\boldsymbol{B}$ except that photoinactivation was applied $5 \mathrm{~min}$ after TBS. Numbers of experiments are indicated in parentheses.

duction, similar experiments to Figure 4 were performed. HFS of three $100 \mathrm{~Hz}$ trains for $1 \mathrm{~s}$ with an interval of $20 \mathrm{~s}$ also induced persistent LTP $(138 \pm 4 \%$ of the control at $60 \mathrm{~min}$ after tetanic stimulation, $n=14$ ) (Fig. $6 A, B$, closed circles). After stable potentiation was established at $60 \mathrm{~min}$ after HFS, ANQX application with UV illumination also caused persistent suppression of potentiated EPSPs and there was no slow time-dependent recovery of EPSPs up to $3 \mathrm{~h}$ after HFS. In another set of experiments, ANQX and UV illumination were applied at $5 \mathrm{~min}$ after HFS. The results were quite similar to the previous experiments (Fig. $6 \mathrm{~A}, \mathrm{C}$, open circles) and did not show a gradual increase in EPSPs for $3 \mathrm{~h}$. Again, initial recovery in the 5 min group was faster than that in 60 min group. Time constants of initial recovery, as calculated with a single exponential fit, were statistically different between the 5 min group $(10.0 \pm 2.1 \mathrm{~min}, n=7)$ and $60 \mathrm{~min}$ group (24.6 $\pm 3.9 \min , n=14 ; p=0.021, t$ test), suggesting that surface delivery of AMPAR is transiently accelerated by HFS and returned to basal levels by $60 \mathrm{~min}$ after induction of LTP. Together,
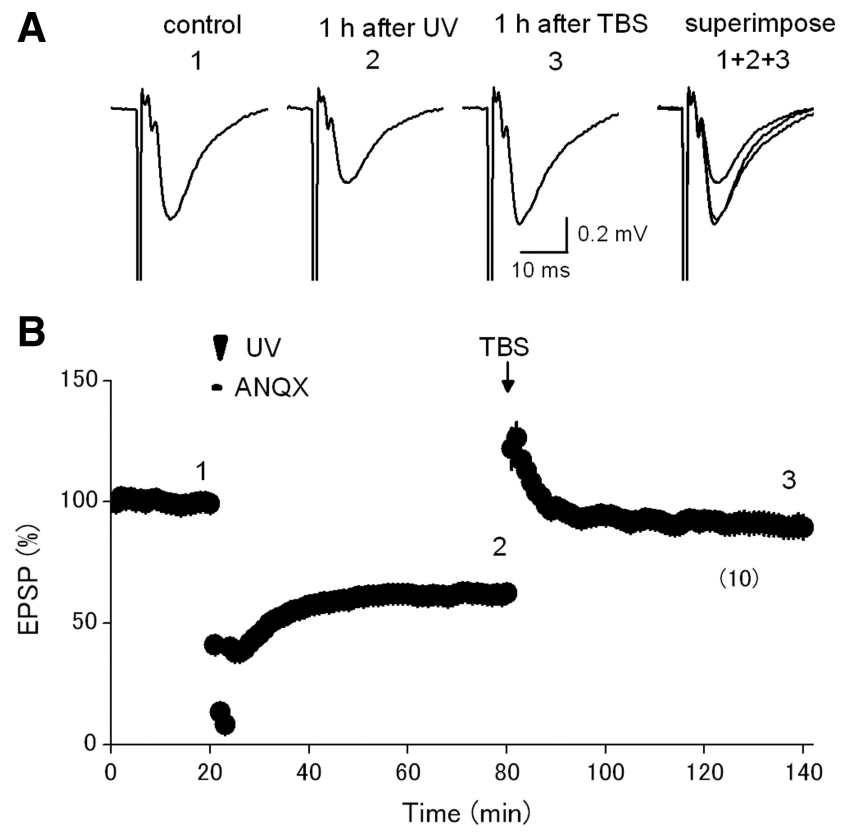

Figure 5. LTP induction by TBS is not affected by the preceding photoinactivation. $\boldsymbol{A}$, Effect of TBS at $60 \mathrm{~min}$ after photoinactivation. $\boldsymbol{B}$, Data in $\boldsymbol{A}$ are normalized with those during the 20 $\min$ before TBS. Numbers of experiments are indicated in parentheses.

acceleration of AMPAR synaptic delivery may take place exclusively in the initial, but not the later, phase of LTP.

Since the time course of washout of unphotolyzed ANQX and side product FQX may vary among different experiments, two pathway experiments are ideal to compare differences in recovery after photoinactivation in control and tetanized inputs in the same recording conditions. Even in the two pathway experiments, in which LTP is induced in one pathway with TBS, it was confirmed that the initial recovery in tetanized input was faster than that in the control input without TBS (Fig. 7A). Photoinactivation was applied at $5 \mathrm{~min}$ after TBS. Time constants of recovery, as calculated with a single exponential fit (Fig. $7 B, C$ ), were statistically different between potentiated $(5.9 \pm 1.6 \mathrm{~min})$ and nonpotentiated inputs $(16.3 \pm 4.1 \mathrm{~min}, n=10, p=0.0075$, paired $t$ test), suggesting that surface delivery of AMPAR is accelerated after LTP induction at $5 \mathrm{~min}$ after TBS.

\section{Discussion}

In this study, it has been demonstrated that extensive local perfusion allowed application of a photoinactivation approach to analyze postsynaptic AMPAR dynamics in acute mouse hippocampal slices. A rather unexpected finding was minimal synaptic delivery of native AMPAR in situ in the resting condition (at least for $3 \mathrm{~h}$ ). Activity-dependent synaptic delivery was shown to be accelerated shortly after LTP induction, but late-phase LTP expression was not accompanied by a sustained increase in synaptic delivery of AMPAR from intracellular reserve pools.

\section{Photoinactivation analysis of native AMPAR in situ}

A previous study demonstrated that photolysis of ANQX was applicable to cultured hippocampal neurons (Adesnik et al., 2005), but the slow perfusion rate of bath application hampered successful photoinactivation of synaptic AMPAR in acute slices, in which the microenvironment of synapses, including the high density of the surrounding neurons and glia, is preserved. In this 

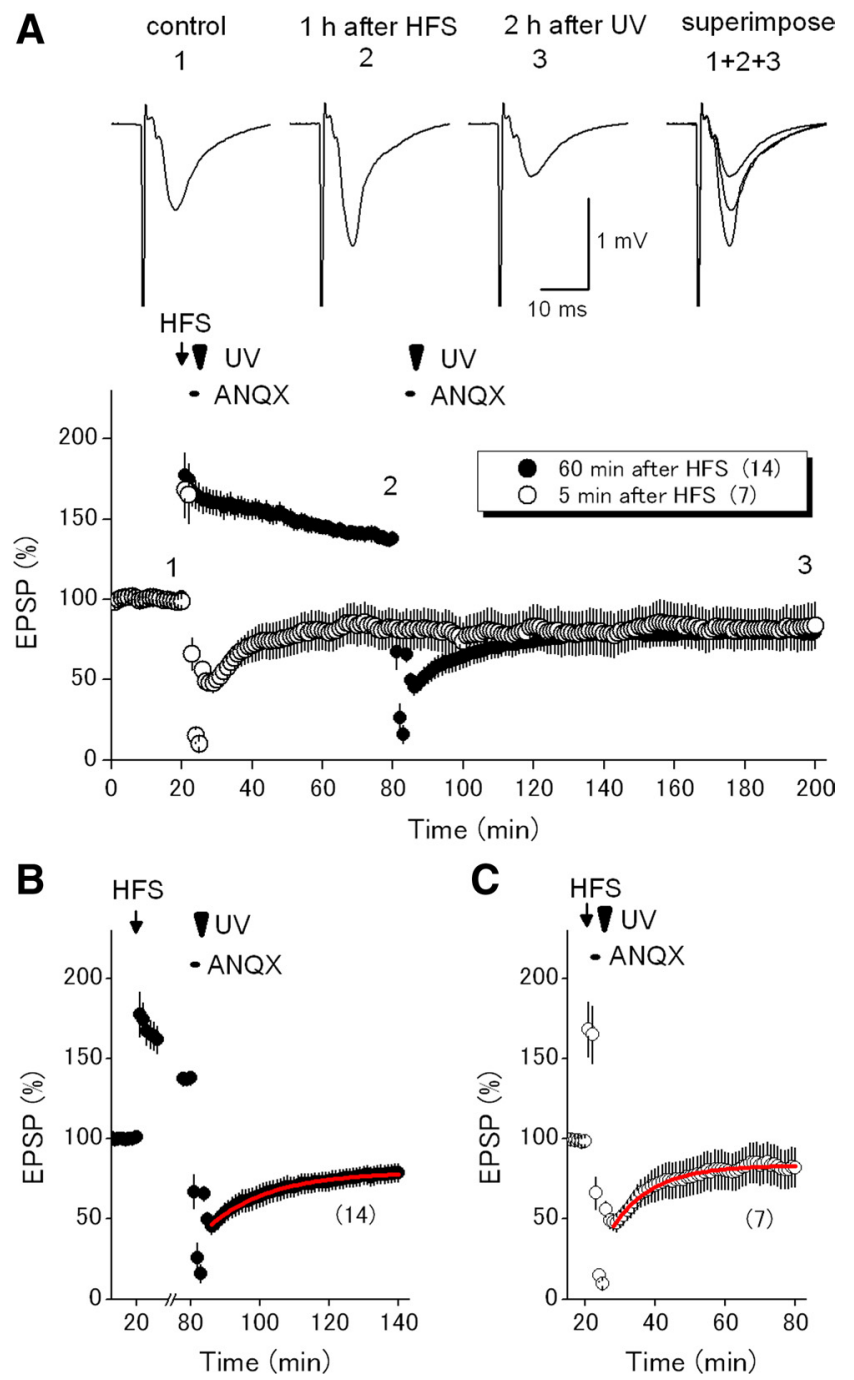

Figure 6. LTP induced by high-frequency stimulation (HFS) accelerates recovery after photoinactivation in the initial, but not in the later, phase. $A$, Effect of photoinactivation either 5 min (open circles) or $60 \mathrm{~min}$ (closed circles) after HFS (100 Hz for $1 \mathrm{~s}$, three times, 20 s interval). $\boldsymbol{B}$, Expanded time course around photoinactivation applied $60 \mathrm{~min}$ after HFS. Red line represents single-exponential fit of recovery. C, Same as $\boldsymbol{B}$ except that photoinactivation was applied 5 min after HFS. Numbers of experiments are indicated in parentheses.

study, therefore, extensive local perfusion system was used for fast application and fast removal of ANQX to the recording sites.

Using this approach, the time course of initial recovery was analyzed quantitatively in this study. Recovery from photoinactivation is thought to reflect two independent processes. One is washout of unphotolyzed ANQX and side product FQX, both reversible blockers of AMPAR (see Fig. 2). Another is synaptic delivery of intracellular reserved AMPAR to postsynaptic sites by receptor traffic mechanisms. The current leading model of AMPAR traffic consists of at least three consecutive steps for their synaptic delivery; i.e., exocytosis from intracellular pools to extrasynaptic sites, lateral diffusion from extrasynaptic to postsynaptic sites, and diffusional trapping to immobilize to postsynaptic sites (Choquet, 2010; Opazo and Choquet, 2011). The rate of synaptic delivery, therefore, reflects all of these processes. It should be noted that AMPAR exocytosis occurs at the dendritic shaft (Yudowski et al., 2007) and perisynaptic sites of the spines (Park et al., 2006; Kennedy et al., 2010). The distant location of these exocytotic spots from postsynaptic sites may cause some delay in reflecting on synaptic enhancement.
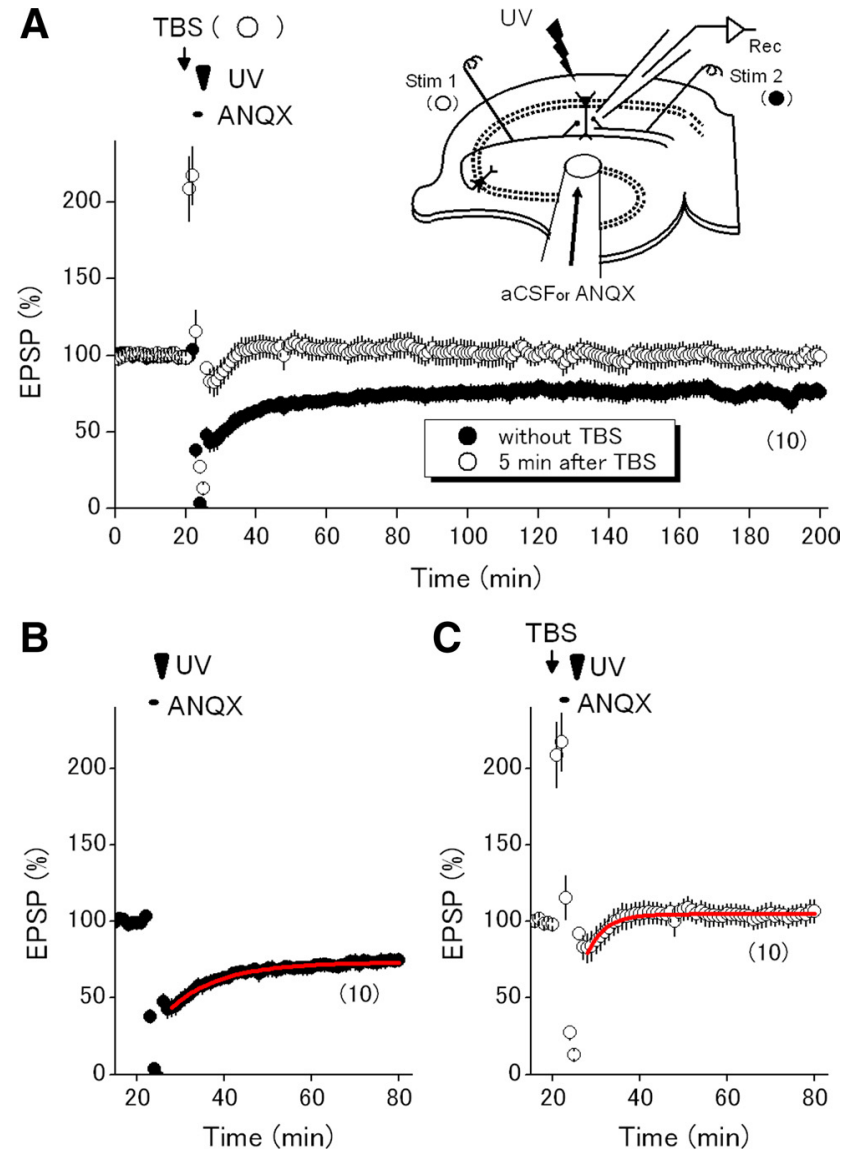

Figure 7. Two pathway experiments for comparison of the recovery phase in potentiated and nonpotentiated inputs. $\boldsymbol{A}$, Effect of photoinactivation on either 5 min after TBS (open circles) or nontetanized input (closed circles) in the same experiments. $\boldsymbol{B}$, Expanded time course around photoinactivation in nontetanized input. Red line represents single-exponential fit of time course of recovery after photoinactivation. C, Same as $\boldsymbol{B}$ except that photoinactivation was applied 5 min after TBS. Numbers of experiments are indicated in parentheses.

Another important notion from the three-step model is that the rate of exocytosis may not directly represent the rate of synaptic delivery of AMPAR, if exocytosis is not a rate-limiting step. Postsynaptic responsiveness to presynaptically released glutamate is determined by the number and single channel conductance of native AMPAR trapped at postsynaptic slots. Increasing size of postsynaptic slots requires complex molecular reactions, including accumulation of cytoskeletal and scaffolding proteins, therefore, it is expected to take some time to fully express plastic changes of postsynaptic responses after surface delivery by exocytosis. It is also possible that, in some conditions, there is a discrepancy between the degree of exocytosis and changes in postsynaptic responses. In fact, overexpression of stargazing enhanced AMPAR exocytosis, but was not sufficient to increase synaptic transmission, suggesting that exocytosis does not directly determine the number of AMPAR trapped at postsynaptic slots (Schnell et al., 2002). It should also be noted that differential changes in synaptic and extrasynaptic AMPAR have been described for overexpression and knockout of $\gamma-8$, a member of the TARP family (Rouach et al., 2005). On the other hand, diffusional trapping at postsynaptic slots is the final step in AMPAR traffic, therefore it is more closely related to synaptic strength, making it a possible ratelimiting step for postsynaptic delivery of AMPAR.

It should be emphasized that the rate of synaptic delivery measured in this study reflects the sum of rates of exocytosis, lateral 
diffusion, and diffusional trapping. During induction of LTP or other plastic changes, the rate of expansion or formation of new postsynaptic density is also attributed to the net rate of recovery after photoinactivation. Localized photoinactivation at subspine levels, possibly using UV laser or multiphoton illumination, may determine rate-limiting steps for multistep synaptic delivery of native AMPAR.

\section{Minimal constitutive synaptic delivery of native AMPAR}

A rather unexpected finding was that postsynaptic expression of AMPAR was quite stable at resting conditions. Previous studies (Nishimune et al., 1998; Lüscher et al., 1999; Lüthi et al., 1999) demonstrated that inhibition of $N$-ethylmaleimide-sensitive factor-dependent exocytosis of GluR2 containing AMPAR suppressed basal transmission, therefore a high rate of AMPAR exocytosis caused turnover in time scales of tens of minutes in hippocampal slices. It was also demonstrated that surface AMPAR is highly mobile, so lateral diffusion is quite fast (Ashby et al., 2006; Heine et al., 2008). In contrast, extremely slow constitutive delivery from intracellular pools in a time scale of hours has been demonstrated for cultured neurons (Adesnik et al., 2005). Inhibition of postsynaptic exocytotic machinery by injection of $N$-ethylmaleimide reduced LTP expression, but did not affect basal transmission in acute slice preparations (Lledo et al., 1998). Although it is difficult to explain all of these findings in a unified model, the finding that blocking postsynaptic exocytosis reduced basal transmission also suggests that the same amount and rate of endocytosis should accompany ongoing exocytosis to maintain stable basal transmission in the resting condition. However, such dynamic equilibrium of exocytosis and endocytosis in the resting condition has not been supported by experimental evidence. Therefore, replacement of postsynaptic AMPAR with intracellular pools is speculated to be quite slow in resting conditions in native hippocampal synapses in situ. Alternatively, the result in this study implies that the size of postsynaptic slots may be quite stable in resting conditions, therefore limiting entry of newly inserted surface extrasynaptic AMPAR to postsynaptic density. A stable size of postsynaptic density most likely serves as a rate-limiting step for synaptic delivery of AMPAR in situ.

\section{Temporal limit in synaptic delivery of native AMPAR during LTP expression}

Applicability of field potential recordings permitted fairly stable recording for several hours, therefore it is useful for study of the temporal difference in the early and late phases of LTP. Several studies suggested that the underlying mechanism of LTP shifts with time over several hours (Nayak et al., 1998; Bayazitov et al., 2007; Tanaka et al., 2008). It was also pointed out that subunit composition is transiently changed within 30 min after LTP induction (Plant at al., 2006; Adesnik and Nicoll, 2007).

This study revealed that activity-dependent synaptic delivery of intracellular receptors is facilitated at $5 \mathrm{~min}$, but not at $60 \mathrm{~min}$, after LTP induction. Accelerated synaptic delivery in the initial phase of LTP is consistent with exocytosis of intracellular AMPAR pools for LTP expression (Lledo et al., 1998; Park et al., 2004). Several studies pointed out that exocytosis of AMPAR occurs over a relatively slow time scale in the order of minutes (Park et al., 2006; Makino and Malinow, 2009), although transmission at a single synapse is potentiated almost instantaneously after LTP induction (Petersen et al., 1998). Together, it is speculated that diffusional trapping of pre-existing mobile extrasynaptic AMPAR (in a time scale of seconds) precedes slower exocytosis of intracellular AMPAR (in a time scale of minutes) to supply the mobile extrasynaptic AMPAR pools required for sustained potentiation (Yang et al., 2008; Petrini et al., 2009).

Another important finding of this study is that postsynaptic delivery of AMPAR is minimal at $60 \mathrm{~min}$ after LTP induction. Many studies have suggested that the expression mechanism of LTP may shift with time and that gradual increases in postsynaptic AMPAR occur over time scales of hours (Bayazitov et al., 2007). Lack of gradual synaptic delivery up to $3 \mathrm{~h}$ was not due to insufficient synaptic activation by the stimulation protocols used in this study (Huang and Kandel, 1994; Nguyen and Kandel, 1997). Protein kinase A-dependent phosphorylation (Esteban et al., 2003), protein synthesis (Nayak et al., 1998; Ju et al., 2004), and neurotrophin-dependent spine enlargement (Matsuzaki et al., 2004; Tanaka et al., 2008) may not be rate-limiting for EPSP enhancement during late-phase LTP.

\section{Methodological considerations}

In addition to numerous studies using optical monitoring of GFP or other macromolecular tagged AMPAR subunits, multiple electrophysiological methods have been adopted to monitor postsynaptic AMPAR dynamics (Liao et al., 1995; Matsuzaki et al., 2001; Andrásfalvy and Magee, 2004). Quantitative measurement required sequential collection of many sample points, therefore time resolution was not fast in these studies. Photoinactivation by ANQX used in this study is a promising alternative approach for studying real-time dynamics of native postsynaptic AMPAR in situ. The applicability of field potential recording is a significant advantage for prolonged observation up to several hours. Mechanisms by which newly inserted extrasynaptic AMPAR stabilize to postsynaptic sites, possibly by interactions with PSD-95 (Stein et al., 2003; Ehrlich and Malinow, 2004) or TARPs (Tomita et al., 2004; Sumioka et al., 2010), are important issues to be resolved using this approach.

In summary, photoinactivation analysis using ANQX in acute hippocampal slice preparations permitted stable recordings for a prolonged observation period, therefore it was useful to analyze temporal dynamics of native AMPAR at intact synapses in completely physiological conditions. Kinetic analysis-clarified native AMPAR was delivered to the postsynaptic sites not in a constitutive, but in an almost exclusively activity-dependent, manner in the hippocampal excitatory synapses. In addition, supporting evidence for the slow postsynaptic delivery of AMPAR in the late phase LTP was not found.

\section{References}

Adesnik H, Nicoll RA (2007) Conservation of glutamate receptor 2-containing AMPA receptors during long-term potentiation. J Neurosci 27:4598-4602.

Adesnik H, Nicoll RA, England PM (2005) Photoinactivation of native AMPA receptors reveals their real-time trafficking. Neuron 48:977-985.

Andrásfalvy BK, Magee JC (2004) Changes in AMPA receptor currents following LTP induction on rat CA1 pyramidal neurones. J Physiol 559:543-554.

Ashby MC, Maier SR, Nishimune A, Henley JM (2006) Lateral diffusion drives constitutive exchange of AMPA receptors at dendritic spines and is regulated by spine morphology. J Neurosci 26:7046-7055.

Bayazitov IT, Richardson RJ, Fricke RG, Zakharenko SS (2007) Slow presynaptic and fast postsynaptic components of compound long-term potentiation. J Neurosci 27:11510-11521.

Borgdorff AJ, Choquet D (2002) Regulation of AMPA receptor lateral movements. Nature 417:649-653.

Bredt DS, Nicoll RA (2003) AMPA receptor trafficking at excitatory synapses. Neuron 40:361-379.

Chambers JJ, Gouda H, Young DM, Kuntz ID, England PM (2004) Photochemically knocking out glutamate receptors in vivo. J Am Chem Soc 126:13886-13887. 
Choquet D (2010) Fast AMPAR trafficking for a high-frequency synaptic transmission. Eur J Neurosci 32:250-260.

Cruz LA, Estébanez-Perpiñá E, Pfaff S, Borngraeber S, Bao N, Blethrow J, Fletterick RJ, England PM (2008) 6-Azido-7-nitro-1,4-dihydroquinoxaline-2,3dione (ANQX) forms an irreversible bond to the active site of the GluR2 AMPA receptor. J Med Chem 51:5856-5860.

Ehlers MD, Heine M, Groc L, Lee MC, Choquet D (2007) Diffusional trapping of GluR1 AMPA receptors by input-specific synaptic activity. Neuron 54:447-460.

Ehrlich I, Malinow R (2004) Postsynaptic density 95 controls AMPA receptor incorporation during long-term potentiation and experience-driven synaptic plasticity. J Neurosci 24:916-927.

Esteban JA, Shi SH, Wilson C, Nuriya M, Huganir RL, Malinow R (2003) PKA phosphorylation of AMPA receptor subunits controls synaptic trafficking underlying plasticity. Nat Neurosci 6:136-143.

Hayashi Y, Shi SH, Esteban JA, Piccini A, Poncer JC, Malinow R (2000) Driving AMPA receptors into synapses by LTP and CaMKII: requirement for GluR1 and PDZ domain interaction. Science 287:2262-2267.

Heine M, Groc L, Frischknecht R, Béique JC, Lounis B, Rumbaugh G, Huganir RL, Cognet L, Choquet D (2008) Surface mobility of postsynaptic AMPARs tunes synaptic transmission. Science 320:201-205.

Huang YY, Kandel ER (1994) Recruitment of long-lasting and protein kinase A-dependent long-term potentiation in the CA1 region of hippocampus requires repeated tetanization. Learn Mem 1:74-82.

Ju W, Morishita W, Tsui J, Gaietta G, Deerinck TJ, Adams SR, Garner CC, Tsien RY, Ellisman MH, Malenka RC (2004) Activity-dependent regulation of dendritic synthesis and trafficking of AMPA receptors. Nat Neurosci 7:244-253.

Kakegawa W, Tsuzuki K, Yoshida Y, Kameyama K, Ozawa S (2004) Inputand subunit-specific AMPA receptor trafficking underlying long-term potentiation at hippocampal CA3 synapses. Eur J Neurosci 20:101-110.

Kamiya H, Shinozaki H, Yamamoto C (1996) Activation of metabotropic glutamate receptor type $2 / 3$ suppresses transmission at rat hippocampal mossy fibre synapses. J Physiol 493:447-455.

Kamiya H, Ozawa S, Manabe T (2002) Kainate receptor-dependent shortterm plasticity of presynaptic $\mathrm{Ca}^{2+}$ influx at the hippocampal mossy fiber synapses. J Neurosci 22:9237-9243.

Kennedy MJ, Ehlers MD (2011) Mechanisms and function of dendritic exocytosis. Neuron 69:856-875.

Kennedy MJ, Davison IG, Robinson CG, Ehlers MD (2010) Syntaxin-4 defines a domain for activity-dependent exocytosis in dendritic spines. Cell 141:524-535.

Larson J, Wong D, Lynch G (1986) Patterned stimulation at the theta frequency is optimal for the induction of hippocampal long-term potentiation. Brain Res 368:347-350.

Liao D, Hessler NA, Malinow R (1995) Activation of postsynaptically silent synapses during pairing-induced LTP in CA1 region of hippocampal slice. Nature 375:400-404

Lledo PM, Zhang X, Südhof TC, Malenka RC, Nicoll RA (1998) Postsynaptic membrane fusion and long-term potentiation. Science 279:399-403.

Lüscher C, Xia H, Beattie EC, Carroll RC, von Zastrow M, Malenka RC, Nicoll RA (1999) Role of AMPA receptor cycling in synaptic transmission and plasticity. Neuron 24:649-658.

Lüthi A, Chittajallu R, Duprat F, Palmer MJ, Benke TA, Kidd FL, Henley JM, Isaac JT, Collingridge GL (1999) Hippocampal LTD expression involves a pool of AMPARs regulated by the NSF-GluR2 interaction. Neuron 24:389-399.

Makino H, Malinow R (2009) AMPA receptor incorporation into synapses during LTP: the role of lateral movement and exocytosis. Neuron 64:381-390.

Malinow R, Malenka RC (2002) AMPA receptor trafficking and synaptic plasticity. Annu Rev Neurosci 25:103-126.

Matsuzaki M, Ellis-Davies GC, Nemoto T, Miyashita Y, Iino M, Kasai H (2001) Dendritic spine geometry is critical for AMPA receptor expression in hippocampal CA1 pyramidal neurons. Nat Neurosci 4:10861092.
Matsuzaki M, Honkura N, Ellis-Davies GC, Kasai H (2004) Structural basis of long-term potentiation in single dendritic spines. Nature 429:761-766.

Nayak A, Zastrow DJ, Lickteig R, Zahniser NR, Browning MD (1998) Maintenance of late-phase LTP is accompanied by PKA-dependent increase in AMPA receptor synthesis. Nature 394:680-683.

Nguyen PV, Kandel ER (1997) Brief theta-burst stimulation induces a transcription-dependent late phase of LTP requiring cAMP in area CA1 of the mouse hippocampus. Learn Mem 4:230-243.

Nishimune A, Isaac JT, Molnar E, Noel J, Nash SR, Tagaya M, Collingridge GL, Nakanishi S, Henley JM (1998) NSF binding to GluR2 regulates synaptic transmission. Neuron 21:87-97.

Opazo P, Choquet D (2011) A three-step model for the synaptic recruitment of AMPA receptors. Mol Cell Neurosci 46:1-8.

Opazo P, Labrecque S, Tigaret CM, Frouin A, Wiseman PW, De Koninck P, Choquet D (2010) CaMKII triggers the diffusional trapping of surface AMPARs through phosphorylation of stargazin. Neuron 67:239-252.

Park M, Penick EC, Edwards JG, Kauer JA, Ehlers MD (2004) Recycling endosomes supply AMPA receptors for LTP. Science 305:1972-1975.

Park M, Salgado JM, Ostroff L, Helton TD, Robinson CG, Harris KM, Ehlers MD (2006) Plasticity-induced growth of dendritic spines by exocytic trafficking from recycling endosomes. Neuron 52:817-830.

Petersen CC, Malenka RC, Nicoll RA, Hopfield JJ (1998) All-or-none potentiation at CA3-CA1 synapses. Proc Natl Acad Sci U S A 95:4732-4737.

Petrini EM, Lu J, Cognet L, Lounis B, Ehlers MD, Choquet D (2009) Endocytic trafficking and recycling maintain a pool of mobile surface AMPA receptors required for synaptic potentiation. Neuron 63:92-105.

Plant K, Pelkey KA, Bortolotto ZA, Morita D, Terashima A, McBain CJ, Collingridge GL, Isaac JT (2006) Transient incorporation of native GluR2-lacking AMPA receptors during hippocampal long-term potentiation. Nat Neurosci 9:602-604.

Rouach N, Byrd K, Petralia RS, Elias GM, Adesnik H, Tomita S, Karimzadegan S, Kealey C, Bredt DS, Nicoll RA (2005) TARP $\gamma-8$ controls hippocampal AMPA receptor number, distribution and synaptic plasticity. Nat Neurosci 8:1525-1533.

Schnell E, Sizemore M, Karimzadegan S, Chen L, Bredt DS, Nicoll RA (2002) Direct interactions between PSD-95 and stargazin control synaptic AMPA receptor number. Proc Natl Acad Sci U S A 99:13902-13907.

Shi SH, Hayashi Y, Petralia RS, Zaman SH, Wenthold RJ, Svoboda K, Malinow R (1999) Rapid spine delivery and redistribution of AMPA receptors after synaptic NMDA receptor activation. Science 284:1811-1816.

Shi S, Hayashi Y, Esteban JA, Malinow R (2001) Subunit-specific rules governing AMPA receptor trafficking to synapses in hippocampal pyramidal neurons. Cell 105:331-343.

Shimizu H, Fukaya M, Yamasaki M, Watanabe M, Manabe T, Kamiya H (2008) Use-dependent amplification of presynaptic $\mathrm{Ca}^{2+}$ signaling by axonal ryanodine receptors at the hippocampal mossy fiber synapse. Proc Natl Acad Sci U S A 105:11998-12003.

Stein V, House DR, Bredt DS, Nicoll RA (2003) Postsynaptic density-95 mimics and occludes hippocampal long-term potentiation and enhances long-term depression. J Neurosci 23:5503-5506.

Sumioka A, Yan D, Tomita S (2010) TARP phosphorylation regulates synaptic AMPA receptors through lipid bilayers. Neuron 66:755-767.

Tanaka J, Horiike Y, Matsuzaki M, Miyazaki T, Ellis-Davies GC, Kasai H (2008) Protein synthesis and neurotrophin-dependent structural plasticity of single dendritic spines. Science 319:1683-1687.

Tomita S, Fukata M, Nicoll RA, Bredt DS (2004) Dynamic interaction of stargazin-like TARPs with cycling AMPA receptors at synapses. Science 303:1508-1511.

Yang Y, Wang XB, Frerking M, Zhou Q (2008) Delivery of AMPA receptors to perisynaptic sites precedes the full expression of long-term potentiation. Proc Natl Acad Sci U S A 105:11388-11393.

Yudowski GA, Puthenveedu MA, Leonoudakis D, Panicker S, Thorn KS, Beattie EC, von Zastrow M (2007) Real-time imaging of discrete exocytic events mediating surface delivery of AMPA receptors. J Neurosci 27:11112-11121. 